\title{
Formulation of a novel HRV classification model as a surrogate fraudulence detection schema
}

\author{
Tan Tian Swee, Kelvin Ling Chia Hiik, Tan Jia Hou, Leong Kah Meng, Mohammed Rafiq Abdul- \\ Kadir, Arief Ruhullah A. Harris, Muhamad Firdaus Mohd Rafi, Leo Bodey, Yii Cheng Tay, Azli \\ Yahya, Joyce Sia Sin Yin, Matthias Tiong Foh Thye, Tengku Ahmad Iskandar Tengku Alang, \\ Sameen Ahmed Malik
}

Medical Implant Technology Group (MediTEG), Frontier Materials Research Alliance, School of Biomedical Engineering and Health Sciences (SKBSK), Faculty of Engineering, Universiti Teknologi Malaysia, Skudai 81310, Johor, Malaysia

* Corresponding author: tantswee@biomedical.utm.my

Article history

Received 24 April 2018

Revised 30 October 2018

Accepted 13 March 2019

Published Online 2 February 2020

\begin{abstract}
Lie detection has been studied since a few decades ago, usually for the purpose of producing a scheme to assist in the investigation of identifying the culprit from a list of suspects. Heart Rate Variability (HRV) may be used as a method in lie detection due to its versatility and suitability. However, since its analysis is not instantaneous, a new experiment is described in this paper to overcome the problem. Additionally, a preliminary HRV classification model is designed to further enhance the classification model which is able to distinguish the lie from the truth for up to $80 \%$.
\end{abstract}

Keywords: Heart Rate Variability (HRV), lie detection, classification model

\section{INTRODUCTION}

A lie is an intentionally false statement to a person or group made by another person or group who knows it is not wholly the truth (Freitas, 2013). Lies can be told for various reasons, and with various amounts of success. One of the factors that determine its success is by how well the person who was told the lie can detect the cue. Therefore, this leads to a conclusion that lying is accompanied by specific perceptible physiological or behavioral alterations, which the very cues are derived from. Such most daily example is a mother tells her child, "Look at me," in order to assure he is telling the truth, because she believes that lying is associated with averting the gaze (Bateson, 1972). Other idiosyncratic behavioral manifestations may be recognized by those close to an individual when he purposefully decides to lie. These may include signs of tension, agitation, respiratory changes, a catch in one's voice, blanching, blushing, etc. However, the same method of lie detection could not be applied as easily to strangers in public. Investigators do not know criminals well enough to detect the slight behavioral alterations the criminals, and interviewers only barely know the interviewees by the brief resumes attached. In the past decades, researches had been done to convert those recognizable signs into more representative qualitative parameters. The progress improved when various biomedical measuring techniques are found. Several methods had been used in the attempt to detect deception including measurement of skin conductance, blood pressure, and respiratory rate as in polygraph test.

Heart Rate Variability (HRV) is a commonly used classification model due to its related parameters. It is the physiological phenomenon of variation in the time interval between heartbeats. It is measured by the variation in the beat-to-beat interval or can be measured by heart murmurs which measures the spectral characteristic such as the amplitude and timing (Shaikh et al., 2012, Sh-Hussain et al., 2012). Previous studies have shown that it is directly affected by the Autonomic Nervous System (ANS). The sympathetic branch of ANS also called 'flight or fight' branch deals with stress and manifests itself in changes in HRV.

This paper describes the works to develop an alternative lie detection scheme using HRV classification model. A lie detection experiment is designed to quantify and qualify the linear parametric (time and frequency domain) analysis differences in both 'deception' and 'truthful' situation. Finally, the results from the analysis are tabulated for future algorithm development that helps to create the most accurate results in detecting deception.

\section{POLYGRAPH MECHANISM}

Polygraph technique has been widely used by police, governmental agencies, and industry to detect deception. However, to date there is still no specific physiological response has ever been identified that is unique to lying (Rosenfield, 1995). On the contrary, the kinds of behavioral and physiological responses associated with deception are also characteristic of arousal, anxiety, and stress to name a few. Therefore, most experiment carried out could not fully distinguish the changes were either made by solely the deceptive intent itself only, or a mixture with accompanying emotions.

In the polygraph technique, the detection of deception depends upon a comparison of the subject's responses to two or more stimuli matched in their presumed ability to arouse the subject. Some of these stimuli may or may not associated with deception. If the individual's responses to these basically similar stimuli are considerably different in the case of those stimuli about which deception is suspected, a 
diagnosis of lying is made. The procedure rests on a number of assumptions, which include an adequate matching of stimuli, as well as differential response on one or more of the parameters being measured (Orne et al., 1972).

A simple version of such test is the card test which is used both in certain field applications and in laboratory studies. A subject is asked to select and remember one of six cards. As the facilitator name each of the cards, he is required to answer "No" each time, thereby "lying" about the card he actually did select. Therefore, the comparison of the physiological response to each of the stimuli will show that the greatest response is evoked by the card selected. The process of selecting the card, then, differentially alters the individual's physiological response to it. However, the simple procedure will not guarantee the greatest physiological response is associated with a selected card. On the contrary, situations varying the consequences of deception, the kind of response required of the subject, his antecedent experience, the kind of parameters being tested, etc., will dramatically affect the incidence with which a selected card will evoke a differentially greater physiological response (Orne et al., 1972). This is one of the factors that make laboratory studies questionable when applied to real situation.

The Cognitive Load hypothesis states that lying requires more cognitive resources compared to truth-telling and decreases the respiratory sinus arrhythmia (RSA). The extra cognitive load is due to the fact that the deceptive person is engaging in additional tasks - such as inferring what others are thinking, "keeping their story straight," monitoring and controlling their behavior - in order to avoid creating the impression that they are lying (Aikins et al., 2010). Thus, by increasing task complexity (e.g., asking a participant to tell the story in reverse order, requiring simultaneous performance on multiple tasks) deceptive individuals should be more detectable (Vrij et al., 2006). HRV has been associated with information-processing ability. The suppression of HRV is hypothesized to indicate an increased capacity for sustained attention (Porges et al., 1996). Furthermore, healthy nonanxious individuals demonstrate reductions in HRV during neuropsychological tests of attention, executive function, and working memory (Middleton et al., 1999; Hansen et al., 2003). When combined with the Cognitive Load hypothesis, lying should produce a lower HRV value theoretically.

Heart rate (HR), like many physiological set points such as blood pressure and temperature, is not a static parameter, but rather changes within a range in reaction to bodily demands. Healthy cardiovascular systems are ready to quickly detect and respond to changing needs placed upon the system in order to restore homeostasis and permit directed activities.

Frequency domain analysis is often more popular than time domain analysis when it comes to interpreting HRV data. The spectral peak in a low frequency band (LF, $0.01-0.15 \mathrm{~Hz}$ ) is thought to be influenced by both parasympathetic and sympathetic activity, while the peak in a high frequency band (HF, $0.15-0.40 \mathrm{~Hz})$ is influenced solely by parasympathetic activity (Malik et al., 1996). Parasympathetic and sympathetic activity are not necessarily reciprocal or antagonistic and cannot be inferred from heart rate changes alone (Paton et al., 2005). For example, tachycardia may be produced by either increased sympathetic activity, decreased parasympathetic activity, both, or even peripheral chemo reflexes (Napadov et al., 2008). The parameters used in frequency domain analysis of HRV are the normalized components, power spectral density of $\mathrm{HF}$ and $\mathrm{LF}$, as well as LF/HF ratio. Meanwhile for time domain analysis, the standard deviation of $\mathrm{NN}$ intervals (SDNN) and the square root of the mean of the squares of the successive differences between adjacent NNs (RMSSD) are the common parameters.

\section{Welch periodogram}

Practical computations of the discrete Fourier Transform (DFT) use the fast Fourier Transform (FFT) for speed advantages. The periodogram, extension of the DFT, is a basic method of estimating power spectral density of a time series. Refer to Eq. (1).

$$
P(f)=\frac{1}{N}\left|\sum_{n=0}^{N-1} X(n) e^{-i 2 \pi f k / L}\right|^{2} \quad k=0,1, \ldots, L-1
$$

By incorporating a weighted windowing function $w(n)$, such as Hamming and Hanning, to the input series, spectral leakage of the periodogram could be reduced. Data near the edges of the time series are given less weight compared to data nearer the center. Thus, the modified periodogram is described in Eq. (2).

Finally, in order to further reduce the variance of the periodogram estimation, the Welch method separates the data series into $\mathrm{N}$ overlapping segments. The Welch method applies a weighting window to reduce spectral leakage, but weighting is applied to each segment. Finally, an averaged PSD is calculated using all segments. Power spectral density by the Welch periodogram is given by where $P_{M, i}(f)$ is the $\mathrm{i}^{\text {th }}$ modified periodogram from the data series. Refer to Eq. (2).

$$
P_{M}(f)=\frac{1}{M U}\left|\sum_{n=0}^{M-1} X(n) w(n) e^{-i 2 \pi f n}\right|^{2} \quad i=0,1, \ldots, L-1
$$

where

$$
U=1 / M \sum_{n=0}^{M-1} w^{2}(n)
$$

\section{Burg periodogram}

Autoregressive spectral estimation methods differ from nonparametric methods as they attempt to model the data instead of estimating the PSD directly. Several modeling methods exist for AR spectrum estimation, but the Burg method is the most common in HRV (Issartel et al., 2006). The power spectrum of a $p^{\text {th }}$ order autoregressive process is given in Eq. (3).

$$
P_{\text {Burg }}(f)=\frac{1}{f_{s}} \frac{\varepsilon_{p}}{\left|1+\sum_{k=1}^{p} a_{p}(k) e^{-2 \pi j k f / f_{s}}\right|^{2}}
$$

where $\varepsilon_{\mathrm{p}}$ is the total least square error, $\mathrm{f}_{\mathrm{s}}$ is the sample rate, and $\mathrm{a}_{\mathrm{p}}$ are the Burg AR model parameters (Carvalho et al., 2003). Meanwhile, Thong et al. (2004) suggests that a model order of $\mathrm{p}=16-20$ is a sound choice for HRV in human IBI resampled at $2-4 \mathrm{~Hz}$.

\section{RESEARCH METHODOLOGY}

A total of 10 participants ( 5 females, 5 males) were recruited to participate in the study. The number of males and females is the same so that there is no inequality or biased factor. It is undeniable that factors such as emotion, stress, and health conditions can affect the heart rate variability lie detector experiment results. To minimize the factors, all subjects chosen are generally happy, stress-free, and healthy before they undergo the lie detector experiment. The recruitment was voluntary without any form of reward or compensation. The study took place in a closed lab in School of Biomedical Engineering and Health Sciences, Universiti Teknologi Malaysia. PowerLab 16/35 and Octal Bio Amp were used for data acquisition in this study. For the software, LabChart Pro 7 was used with "ECG and Volume Pulse Setting" as the settings file. A set of three disposable ECG electrodes was also used on each subject, primed respectively by abrasive gel and alcohol swabs to reduce skin resistance and remove dead skin cells.

Many previous studies have been focusing on lie detection in the field of interrogating to identify criminal from a list of suspects. One of the most recent examples is by Staunton et al. (2011). The method used was playing a situational role, such as letting the participants to involve in a mock crime, followed by interrogating the participants with Guilty Knowledge Test. The weakness in this type of study was the participants do not have the psychology of true criminals and therefore any act of lie is more discernable than the real situation. Besides that, situational role participative method has been reported to leave participants feeling unrelated, and thus has lower motivation for telling lie. Furthermore, the questions asked in such methods only required simple yes and no as a response. Therefore, it was unsuitable for HRV measurement which requires short-term analysis to last for minimum two minutes. 
Therefore, this study suggests another way of conducting lie detection. The method is inspired by a common lie which almost everybody can tell. When complimenting on other people looks, one tends to tell lie depending on the familiarity of the speaker with the listener; the more unfamiliar is the listener to the speaker, to a greater extend a lie is told. The motivation of the lie is undoubtedly to make the listener feel good, so that it assists further possible social interactions between the listener and the speaker. This motivation had been adapted in this study.

In order to play up the situation, four photos of celebrities (Hang Mioku, Jocelyn Wildenstein, Grichka Bogdanoff, and Pete Burns) with extreme facial surgical failure were selected for the study. Although only one out of the four celebrities will be discussed, by providing the chance for participants to choose, this not only equal to acknowledging the different sense of beauty in every participant, but also formed an unconscious acknowledgement of the participants towards the deformity of the celebrities they had chosen. Since the participants are from both sexes, the celebrities chosen are two males and two females. The photos were shown to the participants through a PowerPoint presentation. All of the subjects were asked whether they knew these four celebrities and none of subjects were familiar with them.

The participants were briefed upon the purpose of the study and what they were expected to do in the experiment. Each of them was asked to sit comfortably on a chair facing a laptop. Then, the ECP electrodes were attached to both wrists and the right ankle. Before the experiment started, the signal obtained in the LabChart software was checked.
There were three stages in the experiment. The participants were required to choose one of the ugliest celebrities (they were not told that the photos were celebrities) in the first stage. After that, the comparison photo of the chosen celebrity before and after the plastic surgery was shown. A brief background of the chosen celebrity was revealed to the participants, focusing on the reasons that caused the celebrity to undergo plastic surgery. Then, the participants were encouraged to discuss on the facial features of the celebrity. This is the second stage of the experiment, where the purpose was to obtain the signal when the participants were being truthful, while conditioning their mind by strengthening their perception towards the ugliness of the celebrities after the plastic surgery. The third stage was to force the participants to lie. The participants were told to compliment the facial features of the celebrities.

\section{RESULTS AND DISCUSSION}

Table 1 shows the 10 -subjects results summary of the HRV experiment as categorized per time domain, frequency domain, and time-frequency domain analyses. A total of 5 parameters were adopted for comparison between the truth and deception portion, which were SDNN, RMSSD and pNN50 for the time domain, and LF to HF ratio for both frequency and time-frequency domain analyses. All results were generated using a modified HRVAS MATLAB program originally written by John T. Ramshur.

Table 1 HRV experiment results summary.

\begin{tabular}{|c|c|c|c|c|c|c|c|}
\hline Session & Subject & Gender & $\begin{array}{c}\text { SDNN } \\
\text { (ms) }\end{array}$ & $\begin{array}{c}\text { RMSSD } \\
\text { (ms) }\end{array}$ & $\begin{array}{c}\text { pNN50 } \\
(\%)\end{array}$ & $\begin{array}{l}\text { LFHF } \\
\text { (Welch) }\end{array}$ & $\begin{array}{l}\text { LFHF } \\
\text { (Burg) }\end{array}$ \\
\hline \multirow[t]{10}{*}{ Truth } & 1 & $F$ & 103 & 133.9 & 21.6 & 2.43 & inf \\
\hline & 2 & $F$ & 40.6 & 43.3 & 20.2 & 0.46 & 1 \\
\hline & 3 & $\mathrm{~F}$ & 70.3 & 37.3 & 15 & 2.55 & 3 \\
\hline & 4 & $\mathrm{~F}$ & 40.5 & 16.6 & 0.7 & 2.47 & 3 \\
\hline & 5 & $\mathrm{~F}$ & 71.7 & 90 & 4.3 & 0.92 & 1 \\
\hline & 6 & M & 52.5 & 62.6 & 15.1 & 2.89 & inf \\
\hline & 7 & $M$ & 114.7 & 72 & 26.5 & 1.03 & inf \\
\hline & 8 & $\mathrm{M}$ & 191.5 & 227 & 32.6 & 1.61 & 3 \\
\hline & 9 & $M$ & 41.3 & 28 & 7.7 & 4.59 & 3 \\
\hline & 10 & $M$ & 193 & 114.7 & 61.3 & 1.12 & 0.3 \\
\hline \multirow[t]{10}{*}{ Deception } & 1 & $F$ & 94.9 & 150.1 & 24.4 & 0.34 & 0.5 \\
\hline & 2 & $F$ & 51 & 53.5 & 20.9 & 0.49 & 0.2 \\
\hline & 3 & $\mathrm{~F}$ & 80.1 & 47.4 & 18.9 & 2.26 & 6 \\
\hline & 4 & $\mathrm{~F}$ & 50.6 & 60 & 2 & 0.5 & 1 \\
\hline & 5 & $\mathrm{~F}$ & 36.7 & 22.7 & 1.9 & 7.32 & inf \\
\hline & 6 & M & 86.6 & 104.5 & 19.4 & 0.69 & 1 \\
\hline & 7 & M & 196 & 130 & 47.3 & 0.94 & inf \\
\hline & 8 & $M$ & 190.9 & 279.6 & 47.4 & 0.46 & 0 \\
\hline & 9 & $\mathrm{M}$ & 29.1 & 28.8 & 4.5 & 2.84 & 1 \\
\hline & 10 & $M$ & 115 & 102.7 & 54.3 & 2.35 & 3 \\
\hline
\end{tabular}

Heart Rate Variability (HRV)

SDNN: Standard deviation of the NN (R-R) intervals

RMSSD: Root mean square of successive differences

pNN50: The proportion of NN50 divided by the total number of NN (R-R) intervals

Except for the LF to HF ratio of the time-frequency domain analyses which contains infinities, the box plots showing the means and the data spread per selected parameter were obtained. For gender relevance of the HRV experiment, the male and female results were separately plotted together with the overall population results. See Figures 1-4 below. Based on the data, specifically the averages of the five selected parameters in both truth and deception sessions, a classification tree had been created as shown in Figure 5. As it can be seen, the classification tree is initially separated by gender because of two time-domain parameters - SDNN and RMSSD. As part of the design, equal weights had been given for each of the five HRV analyses parameters used. This is reflected by a score of 1 for every satisfied condition. 


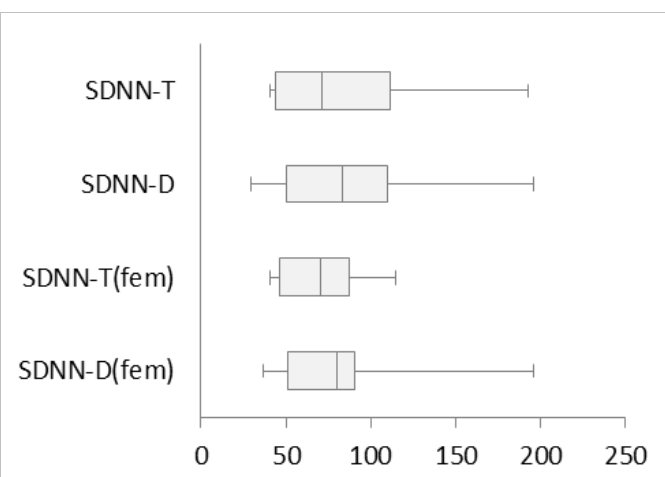

(a)

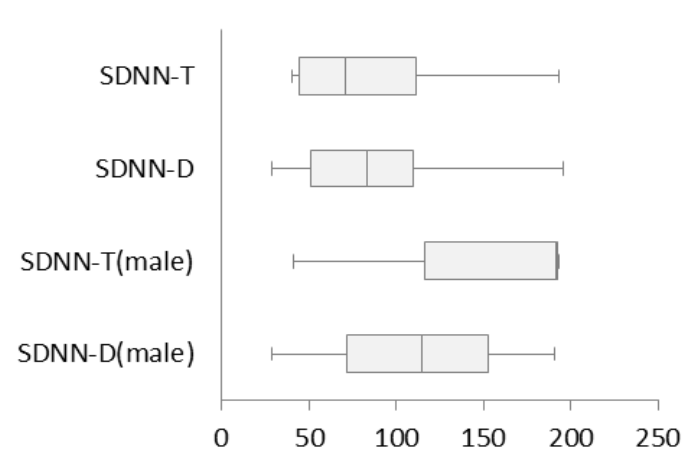

(b)

Fig. 1 SDNN data for truth (SDDN-T) and deception (SDDN_D) sessions. Figure 1a shows female data below overall data and Figure $1 \mathrm{~b}$ shows male data.

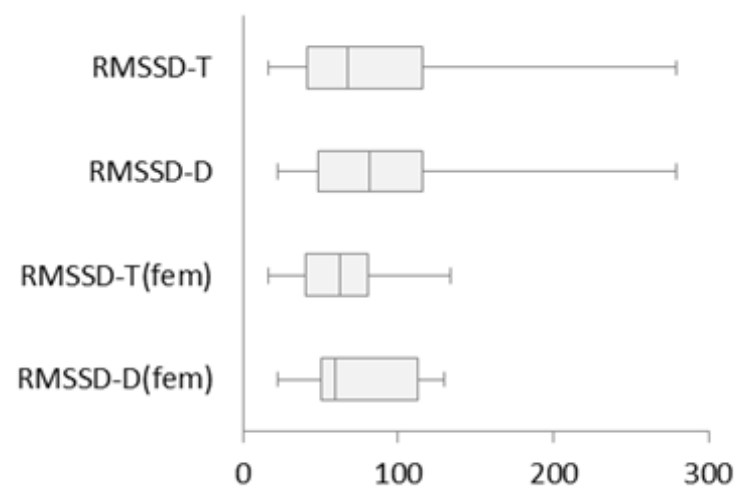

(a)

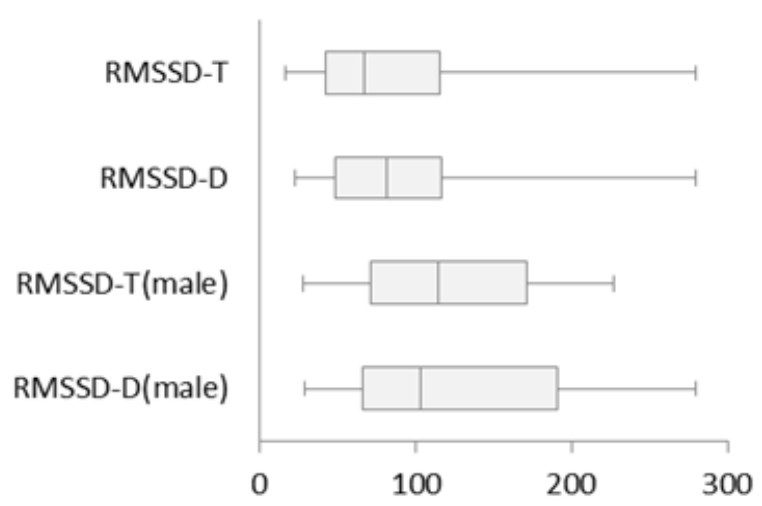

(b)

Fig. 2 RMSSD data for truth (RMSSD-T) and deception (RMSSD_D) sessions. Figure 2(a) shows female data below overall data and Figure 2(b) shows male data.

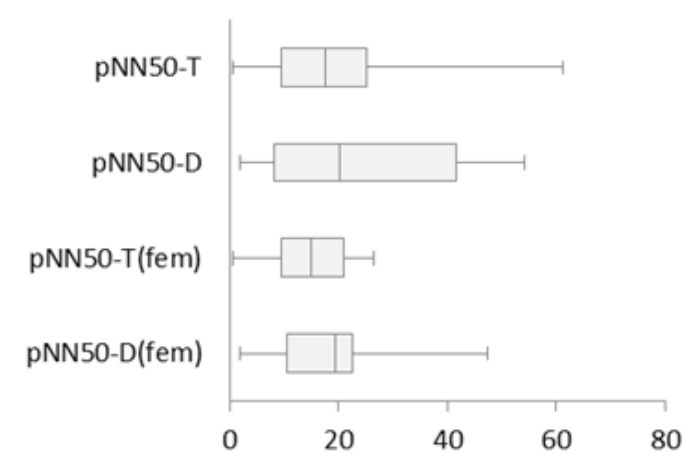

(a)

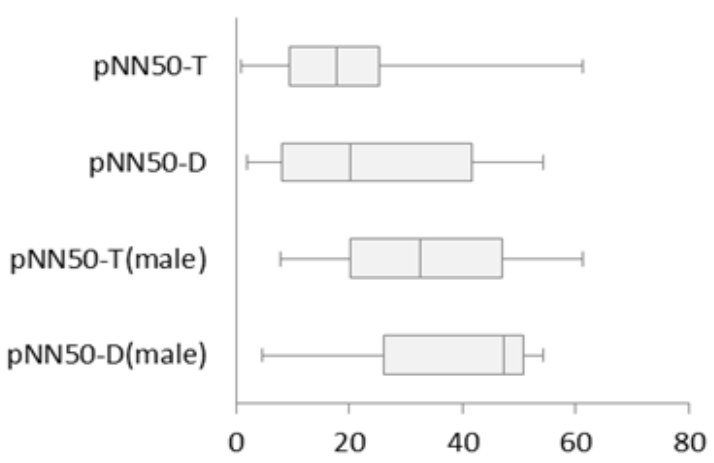

(b)

Fig. 3 pNN50 data for truth (pNN50-T) and deception (pNN50-D) sessions. Figure 3(a) shows female data below overall data and Figure 3 (b) shows male data.

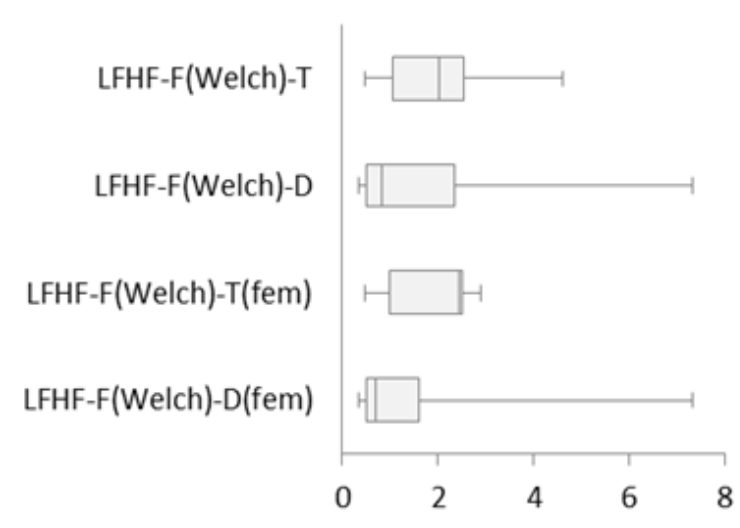

(a)

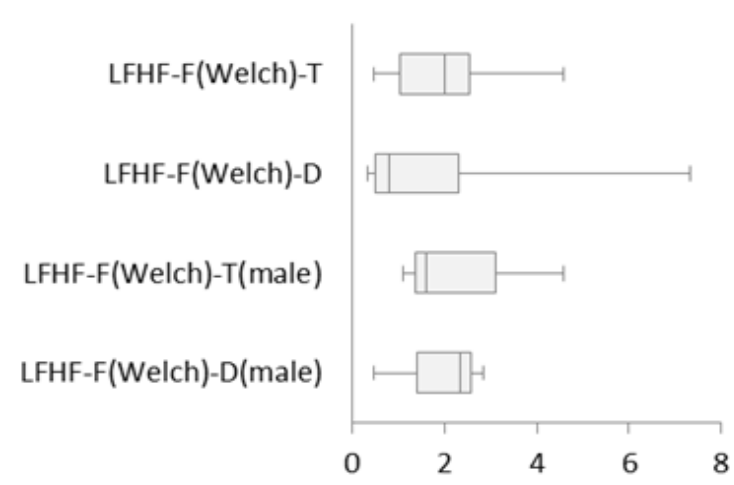

(b)

Fig. 4 Frequency domain LF to HF ratio for truth (LFHF-F(Welch)-T) and deception (LFHF-D(Welch)-D) sessions. Figure 4a shows female data below overall data and Figure $4 \mathrm{~b}$ shows male data. 


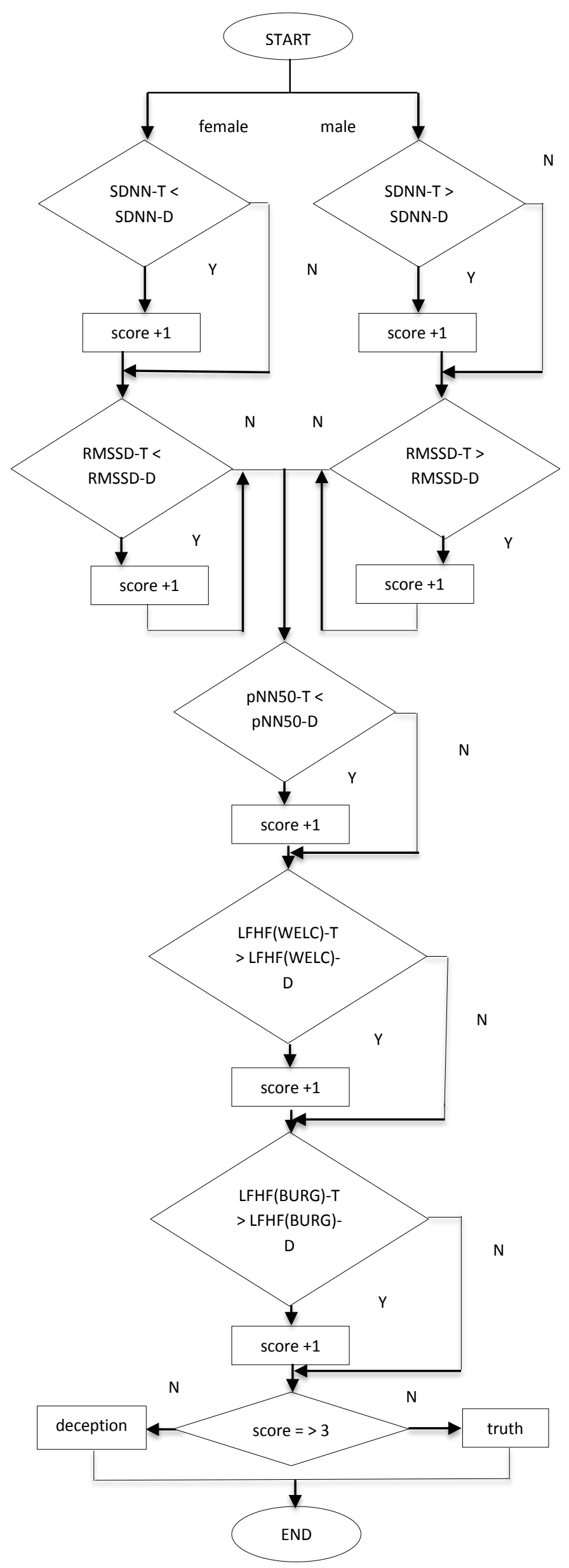

Fig. 5 HRV analyses classification tree for lie detection.
Using the classification tree as a reference, a scoring table (Table 2 ) is subsequently produced. From here, it can be seen that 8 out of 10 $(80 \%)$ subjects had a score of 3 or above which this study has designed to be the threshold for discriminating between telling the truth and deception. In terms of gender, the classification tree has an absolute discrimination performance of $80 \%$ (4/5) for male and $80 \%(4 / 5)$ for female for a combined performance of $80 \%$. Classification accuracy was $80 \%$ due to physiological nature of the heart characteristic of people who lie. It is usually normal for human to show anxiety and nervousness when they lie. The remaining $20 \%$ of the misclassification is due to several factors. One of the factor is the subject is unusually calm in answering the questions. Other than that, the subject is used to and good at lying to people while feeling no guilt and nervousness. To improve the misclassification of data, more unexpected set of questions should be asked. In this way, the liars do not have the inconsistencies and time to react to the unexpected questions. Another measure included on the table are the points obtained per subject and per gender group. This gives rise to the percentage of conditions satisfied over the maximum possible conditions that can be met. As a group, it shows that females and males have the same weighted performance discrimination. However, the total amount of HRV scores obtained by males are 19 while the females are 16. A higher HRV scores means that stress or accumulated stress can be tolerated with a stronger ability. Males have higher HRV scores than females show that males are better at lying. The male subjects can control their heart beat rate in a more controlled rate than the female subjects.

The classification technique used in the HRV classification model presented in this study was initiated by inspecting key single HRV analyses parameters, followed by building a classification tree based on each parameter results. SDNN, RMSSD, and pNN50 were selected as they represent short term time domain analyses while LF to HF spectral power ratios were used for both frequency (Welch) and time-frequency (Burg) domain analyses. Power spectral ratio change had been shown to detect physiological and temporary physical and psychological stress conditions in several studies (Orsila et al., 2008). The use of a classification tree itself in conjunction with HRV analyses as a classification technique is not new. Melillo et al, (2014) developed an automatic coronary heart failure severity assessment system based on long-term HRV analyses. It likewise makes use of intelligible if-then rules using linear and non-linear parameters (Melillo et al., 2014).

As mentioned, the classification tree model was designed based on inspection of the parameter measurements. The classification conditions were based on comparing truth and deception sessions from which the maximum number of subjects will obtain the highest possible score. It does not depend on what related previous studies show otherwise. For example, Delaney and Brodie (2000) had shown that psychological stress decreases HF and increases LF and therefore increases LF to HF ratio. This is not in alignment with the classification tree presented here where the LF to HF ratio condition was designed such that a lower LF to HF ratio during deception session gets a score. Similarly, a work by Ramaekers et al. (1998) emphasized that a higher expression of negative emotions is related to higher vagal tone. This meant that a low RMSSD value indicates high stress. The classification tree here adopts this finding for male subjects only.

The objective of this study however is to set a classification tree conditions based on actual measurements. To improve confidence in the viability of the classification model used, it is expected that more subjects should be tested. The more accurate performance measure can then be obtained by using an established classification tree and testing it against other subjects and other testing conditions.

The division according to gender at the beginning of the regression tree is supported by Sato et al. (2004). Although in their research it is noted that the difference between male and female subjects is at their sympathetic dominance which is more represented by LF/HF ratio, nevertheless, it also promises a potential of difference in time-domain parameter such as SDNN.

The accuracy of the HRV classification model developed might have been affected by several other factors. One of the factors is the change in breathing pattern. Changes in respiration reflect the changes mediated by the baroreceptor reflex as the breathing pattern changes (Rainville et al., 2006). Besides, emotion might have some effect on the 
result as well. McCraty et al. (1995) suggested that positive emotion will induce a shift to higher frequency ranges.

In addition, the personalities and characteristic of the subjects is also one of the factors that lower the accuracy of the HRV classification model. For example, panickers have higher heart rates with least HRV, which indicates low levels of cardiac vagal tone (Friedman et al., 1998) This creates anxiety, which is accompanied by somatic manifestations that suggest marked changes in autonomic nervous system (ANS) activity, such as rapid heart rate, shortness of breath, and sweating. These symptoms are then viewed as a sign of sympathetic (SNS) activation, which affects the interpretation of result. In order to improve the classification model, it is suggested in future research that electrode attachment should be located at torso instead of limbs. This is because it is observed that the participants tend to move especially when telling lie.

Table 2 Score table produced after applying the classification tree on the HRV analysis data.

\begin{tabular}{|c|c|c|c|c|c|c|c|c|c|}
\hline Subj & Sex & SDNN & RMSSD & pNNx & $\begin{array}{l}\text { F-LFHD } \\
\text { (Freg) }\end{array}$ & $\begin{array}{l}\text { F-LFHD } \\
\text { (T-Freg) }\end{array}$ & Total & $\begin{array}{l}\text { Total per } \\
\text { gender }\end{array}$ & $\begin{array}{l}\% \text { of score of } \\
3 \text { and above } \\
\text { per } \\
\text { total(gender) }\end{array}$ \\
\hline 1 & $\mathrm{~F}$ & 0 & 0 & 1 & 1 & 1 & 3 & & \\
\hline 2 & $\mathrm{~F}$ & 1 & 1 & 1 & 0 & 1 & 4 & & \\
\hline 3 & $\mathrm{~F}$ & 1 & 1 & 1 & 1 & 0 & 4 & & \\
\hline 4 & $\mathrm{~F}$ & 1 & 1 & 1 & 1 & 1 & 5 & 16 & 80 \\
\hline 5 & $\mathrm{~F}$ & 0 & 0 & 0 & 0 & 0 & 0 & & \\
\hline 6 & $\mathrm{M}$ & 1 & 1 & 1 & 1 & 1 & 5 & & \\
\hline 7 & $M$ & 1 & 1 & 1 & 1 & 0 & 4 & & \\
\hline 8 & $\mathrm{M}$ & 1 & 1 & 1 & 1 & 1 & 5 & & \\
\hline 9 & $M$ & 1 & 1 & 0 & 1 & 1 & 4 & 19 & 80 \\
\hline 10 & $M$ & 1 & 0 & 0 & 0 & 0 & 1 & & \\
\hline
\end{tabular}

Furthermore, more subjects would be needed in future research to assist in the improvement of the classification suggested in this study. By having more subjects, more groups of participants with certain specific characteristics could be identified. A better average value of the data can be determined if larger sample size is used and errors can be avoided from testing a small number of possible atypical samples. Larger sample sizes provide more data despite more time commitments. The average value of a quality among tested samples can be determined in larger sample sizes. In other words, a larger sample size can have a precise mean. The outliers can be easily pinpointed. The margin of error will decrease when the sample size increases. In this study, the only group identified was based on gender, which is not adequate for extensive public investigation. Furthermore, future research should be accompanied with additional subjects for the sole purpose of testing the classification model generated. However, the optimum number of subjects for this kind of investigation should be from 5 to 25 according to Creswell (1998). Morse (1994) suggests that at least six subjects must participate in the study. It is because this experiment falls under the category of phenomenological studies which is used to describe how human beings experience a certain phenomenon. This is to verify that the classification model can be used to detect deception outside of the pool of participants who contributed to the development of the classification model.

\section{CONCLUSION}

A HRV lie detection model was developed in this study. In order to cater for the requirements of HRV of needing a minimum of 2 minutes for data acquisition, a new method of conducting the experiment was also designed. This was followed by analyzing the parameters and determining the key parameters which could help to identify truth and lie condition of the subjects. The classification tree produced was able to achieve a preliminary accuracy of $80 \%$. By improving the data acquisition method and increasing the number of participants used for building the classification, further increase in accuracy will be highly expected.

\section{ACKNOWLEDGEMENT}

The authors would like to express their gratitude to Universiti Teknologi Malaysia and the Ministry of Higher Education (MOHE) Malaysia for supporting this research under Research University Grant (RUG), number R.J130000.7651.4C238. In addition, the authors would also like to thank the Research Management Center (RMC) - UTM for supporting this research.

\section{REFERENCES}

Aikins, D. E., Martin, D. J., \& Morgan, C. A. (2010). Decreased respiratory sinus arrhythmia in individuals with deceptive intent. Psychophysiology, 47(4), 633-636.

Bateson, G. (1972). Steps to an ecology of mind: Collected essays in anthropology, psychiatry, evolution, and epistemology. Chicago: University of Chicago Press.

Carvalho, J. L. A., Rocha, A. F., Junqueira Jr, L. F., Neto, J. S., Santos, I., \& Nascimento, F. A. O. (2003, September). A tool for time-frequency analysis of heart rate variability. Engineering in Medicine and Biology Society, 2003. Proceedings of the 25th Annual International Conference of the IEEE (Vol. 3, pp. 2574-2577). https://ieeexplore.ieee.org/document/1280441

Creswell, J. W. (1998). Qualitative inquiry and research design: Choosing among five traditions. Thousand Oaks, CA: Sage Publications.

Delaney, J. P. A., \& Brodie, D. A. (2000). Effects of short-term psychological stress on the time and frequency domains of heart-rate variability. Perceptual and motor skills, 91(2), 515-524.

Freitas-magalhães, A. (2013). The face of Lies. FEELab Science Books.

Friedman, B. H., \& Thayer, J. F. (1998). Anxiety and autonomic flexibility: A cardiovascular approach. Biological Psychology, 47(3), 243-263.

Hansen, A. L., Johnsen, B. H., \& Thayer, J. F. (2003). Vagal influence on working memory and attention. International Journal of Psychophysiology, 48(3), 263-274.

Issartel, J., Marin, L., Gaillot, P., Bardainne, T., \& Cadopi, M. (2006). A practical guide to time - frequency analysis in the study of human motor behavior: The contribution of wavelet transform. Journal of motor behavior, 38(2), 139-159.

Malik, M., Bigger, J. T., Camm, A. J., Kleiger, R. E., Malliani, A., Moss, A. J., \& Schwartz, P. J. (1996). Heart rate variability standards of measurement, physiological interpretation, and clinical use. European heart journal, 17(3), 354-381.

McCraty, R., Atkinson, M., Tiller, W. A., Rein, G., \& Watkins, A. D. (1995). The effects of emotions on short-term power spectrum analysis of heart rate variability. The American journal of cardiology, 76(14), 1089-1093.

Melillo, P., Pacifici, E., Orrico, A., Iadanza, E., \& Pecchia, L. (2014, January). Heart rate variability for automatic assessment of congestive heart failure severity. L. M. Roa (Ed.), XIII Mediterranean Conference on Medical and Biological Engineering and Computing 2013 (pp. 1342-1345). Springer International Publishing.

Middleton, H. C., Sharma, A., Agouzoul, D., Sahakian, B. J., \& Robbins, T. W. (1999). Contrasts between the cardiovascular concomitants of tests of planning and attention. Psychophysiology, 36(05), 610-618.

Morse, J. M. (1994). In N. K. Denzin \& Y. S. Lincoln (Eds.), Designing funded qualitative research. Handbook of qualitative research ( $2^{\text {nd }}$ Edition). Thousand Oaks, CA: Sage.

Napadow, V., Dhond, R., Conti, G., Makris, N., Brown, E. N., \& Barbieri, R. (2008). Brain correlates of autonomic modulation: combining heart rate variability with fMRI. Neuroimage, 42(1), 169-177.

Orne, M. T., Thackray, R. I., \& Paskewitz, D. A. (1972). On the detection of deception: A model for the study of the physiological effects of 
psychological stimuli. In N. S. Greenfield \& R. A. Sternbach (Eds.) Handbook of psychophysiology (pp.743-785). New York: Holt, Rinehart \& Winston.

Orsila, R., Virtanen, M., Luukkaala, T., Tarvainen, M., Karjalainen, P., Viik, J., \& Nygard, C. H. (2008). Perceived mental stress and reactions in heart rate variability-a pilot study among employees of an electronics company. International Journal of Occupational Safety and Ergonomics (JOSE), 14(3), 275-283

Paton, J. F. R., Boscan, P., Pickering, A. E., \& Nalivaiko, E. (2005). The yin and yang of cardiac autonomic control: Vago-sympathetic interactions revisited. Brain research reviews, $49(3), 555-565$.

Porges, S. W., Doussard-Roosevelt, J. A., Portales, A. L., \& Greenspan, S. I. (1996). Infant regulation of the vagal "brake" predicts child behavior problems: A psychobiological model of social behavior. Developmental psychobiology, 29(8), 697-712.

Rainville, P., Bechara, A., Naqvi, N., \& Damasio, A. R. (2006). Basic emotions are associated with distinct patterns of cardiorespiratory activity. International journal of psychophysiology, 61(1), 5-18.

Ramaekers, D., Ector, H., Demyttenaere, K., Rubens, A., \& Van der Werf, F. (1998). Association between cardiac autonomic function and coping style in healthy subjects. Pacing and clinical electrophysiology, 21(8), 15461552.

Rosenfeld, J. P. (1995). Alternative views of Bashore and Rapp's (1993) alternatives to traditional polygraphy: A critique. Psychological Bulletin 117(1), 159-166.
Sato, N., \& Miyake, S. (2004). Cardiovascular reactivity to mental stress: relationship with menstrual cycle and gender. Journal of physiological anthropology and applied human science, 23(6), 215-223.

Shaikh Salleh, S. H., Tan, T. S., Sh-Hussain, H., Ibrahim, A., Kamarul, A., Ismail, K., Noor, A. M., \& Oemar, H. (2012). Heart Murmur Diagnostic System (HMDS). Imaging and Signal Processing in Health Care and Technology / 772: Human-Computer Interaction / 773: Communication, Internet and Information Technology (Baltimore, U. S. A., 14-16 May 2012). https://www.actapress.com/Content_Of_Proceeding.aspx?Proceedi $\operatorname{ngID}=734$

Sh-Hussain, H., Salleh, S.-H., Ariff, A. K., Alhamdani, O., Tian-Swee, T., Noor, A. M., Oemar, H. \& Yusoff, K. (2012). Application of multipoint auscultation for heart sound diagnostic system (MAHDS). In 2012 11th International Conference on Information Science, Signal Processing and their Applications (ISSPA) (pp. 836-841). https://ieeexplore.ieee.org/ document/6310669/authors\#authors

Staunton, C., \& Hammond, S. (2011). An investigation of the guilty knowledge test polygraph examination. Journal of Criminal Psychology, 1(1), 1-14.

Thong, T., McNames, J., Aboy, M., \& Oken, B. (2004, June). Averaged Lomb periodogram for nonuniform sampling. International Conference Biosignal (Vol. 4). https://pdfs.semanticscholar.org/e73d/25f16919419af315b4f7b40 5ebca2ebc13fd.pdf

Vrij, A., Fisher, R., Mann, S., \& Leal, S. (2006). Detecting deception by manipulating cognitive load. Trends in cognitive sciences, 10(4), 141-142. 